\title{
Digital Rights Management for the Online Music Business
}

\author{
Sai Ho Kwok
}

\begin{abstract}
Digital rights management has become a pressing concern for the online music business. Existing digital rights management systems are backed by two license management models, the tethered model and the untethered model. These two license management models focus on the management of payments and usage rights. The problems with these models are that the tethered model forces consumers to be online, while the untethered model provides relatively less security to the license residing locally. This paper proposes an enhanced license management model for the online music business, which integrates both models together and thus enables online and offline purchasing.
\end{abstract}

Additional Key Words and Phrases: digital rights management, intellectual property, license management, electronic commerce, electronic business, online music business.

\section{INTRODUCTION}

Five major music labels, Sony Music Inc., BMG Entertainment, EMI Recorded Music, Warner Music Group, and Universal Music, together with many small/medium-sized music companies have already expressed their intentions to offer digital downloads via online music business sites. It is clear that if digital trading is to grow dramatically, digital rights management becomes an important issue to resolve. Digital rights management (DRM) refers to the process of honoring copyright provisions, license terms and usage agreements established by the owners of the intellectual property [1]. DRM generically refers to a piece of technology sitting on a server or a desktop computer that encapsulates, controls and manages contents. In commercial digital rights management systems, there are two competing license management models, tethered and untethered models. These models differ in where the DRM technology is housed and how the digital rights are distributed. In the tethered model, used by Microsoft [14], Intel [6], IBM [5], and Kwok et al. 9], consumers must be online to purchase digital music. License distribution and management are achieved by a license services center where centralized license storage and centralized security are used. In the untethered model, promoted by InterTrust [7], consumers store licenses on their own computers and are able to make purchases offline with a local DRM services center; payment is made at a later date. The untethered model is designed to promote music super-distribution models [12] in which consumers can share files in a viral Napster-like fashion and in which consumers can make micro-payments on a song-by-song basis or on a subscription basis. Revenues could be generated through such super-distribution activities. The trade-off is that the DRM becomes a highly complex application because a local DRM service center is needed and it caused delay and interruption in rendering the music.

Addresses: Department of Information and Systems Management, The Hong Kong University of Science and Technology, Clear Water Bay, Kowloon, Hong Kong SAR, China. Email: jkwok@ust.hk

Permission to make digital/hard copy of part of this work for personal or classroom use is granted without fee provided that the copies are not made or distributed for profit or commercial advantage, the copyright notice, the title of the publication, and its date of appear, and notice is given that copying is by permission of the ACM, Inc. To copy otherwise, to republish, to post on servers, or to redistribute to lists, requires prior specific permission and/or a fee.

C2001 ACM 1073-0516/01/0300-0034 \$5.00 
In a recent paper reviewing the present status and prospects for the Internet, Kahn and Cerf (who are the co-designers of the TCP/IP Internet protocol and the architecture of the Internet) note: "Many of the concerns about intellectual property protection are difficult to deal with, not because of fundamental limits in the laws, but rather by technological and perhaps management limitations in knowing how best to deal with these issues." In the online music business, we basically do not know whether the tethered model or the untethered model can bring in more revenue, and we also do not know whether or not we should have rights management to support a pay-per-view payment model (which is a new concept to many traditional consumers) in the first place. However, we believe that if digital rights management is used, a combined approach is more appropriate for a practical online music business model because DRM is a tool to facilitate online business and should not influence or constrain the business in any way by limiting either online or offline purchasing. This study proposes an enhanced license management model for DRM to support both online and offline purchasing models.

Hartung and Ramme [4] surveyed some DRM standardizations (including MPEG-4 and SDMI). The MPEG-4 Intellectual Property Management and Protection (IPMP) framework [8] is, to a certain extent similar our enhanced model, in which the DRM information can be included in the content container or distributed separately. However, IPMP does not specifically address the online and offline payment issues using license management.

The major contributions of the paper are (1) a proposal of an enhanced license management model for the online music business that supports both online and offline purchasing; and (2) an illustration of the DRM operations in the enhanced license management model.

\section{DIGITAL RIGHTS MANAGEMENT}

In the online music business, digital rights management involves specifying and associating rights with digital music, placing controls on the music to enforce rights, enabling access checks, and tracking permission usage and payment. In particular, the required capabilities contain: (1) rights specification and rights label management; (2) content protection, rights enforcement, and trusted rendering; (3) rights authorization; (4) rights tracking; and (5) security and commerce infrastructure. Different transactions occur between entities during music packaging, distribution, and usage [11]. Managing rights in all of these transactions is necessary. Figure 1 summarizes the involved rights management capabilities in different transactions.

There are some commercial digital rights management systems for the online music business supporting these capabilities. They include Windows Media Rights Manager by Microsoft [14], Electronic Music Management System (EMMS) by IBM [5], Intel Software Integrity System (ISIS) by Intel [6], and MetaTrust by InterTrust Technologies [7]. These DRM solutions require rights insertion and rights enforcement processes. In addition, a license management process is also needed for managing license documents.

Rights Insertion: Rights insertion is a process to assign business rules and conditions, together with the identities of concerned parties, to the music file. The concerned parties in the online music business include music creators, owners, distributors, and consumers. Technologies for embedding identity information consist of digital certification (usually for any individual identity) and digital watermarking (for company identity). The rights insertion usually takes place at the music company and the distribution site. The owner/creator identity is inserted into the music file using both digital certification and digital watermarking at the music company. Business rules and conditions are laid down on a licensing document at the music company or the distribution site or both. To meet new circumstances, opportunities and challenges, additional rules for the use of the music file may be needed for value chain partners, so that distributor may insert other rights into 
the music. For example, consumer information including user' s certificate or user' s keys may be added to the license document to certify that he/she is the legitimate buyer of the music. A digital music file with an associated license document is known as rightsprotected music.

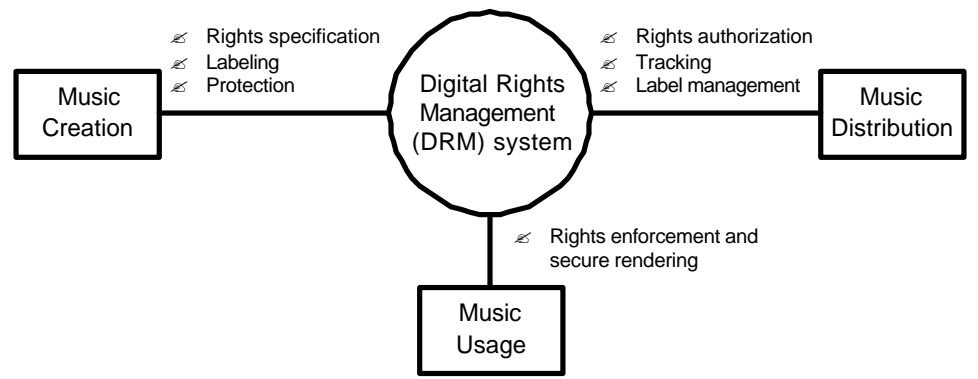

Figure 1: Major transactions in digital rights management: music creation, music distribution, and music usage.

Rights Enforcement: There are two types of rights enforcement, namely active enforcement and passive enforcement. In normal situations, digital rights management systems perform active rights enforcement whenever the music file is being played. This enforcement is a built-in function in the music player. For example, Windows Media Rights Manager [14] by Microsoft conducts active enforcement within the Media Player. When the music file or the license document is corrupted by intentional or unintentional attacks, active enforcement may fail to verify and follow the business rules and conditions associated with the music file. The DRM system will not notice this until passive enforcement is performed. Passive enforcement is an offline ownership verification process. The passive enforcement process takes place when a suspicious music file is found and the process usually checks the hidden owner identities represented by digital watermarks. These hidden watermarks cannot be easily detected and modified by attackers and they are therefore needed when passive enforcement is included in the DRM solution. Although passive rights enforcement is so important to DRM, none of the existing commercial DRM systems, to the best of our knowledge, have implemented this with digital watermarking technology.

License Management: After the licensing document has been created, license management is required for managing the license and payment effectively. License management refers to issuing, hosting, and verifying the license. There are basically two license management models - tethered and untethered models used in commercial DRM systems. The categorization of these models is based on where the DRM technology is housed and how digital rights are distributed. Different payment models use different license management models. For instance, online payment systems use the tethered model, while offline payment systems employ the untethered model. Existing commercial DRM systems support either the tethered or the untethered model, but not both [13]. Comparisons between the two models are given in Table 1.

\subsection{License Management in Existing Commercial DRM systems}

License: There are two universal formats for specifying rights and issuing conditions associated with the use and protection of digital content. They are eXtensible rights Markup Language (XrML) [2] and Digital Property Rights Language (DPRL) [3]. These formats enable content owners to describe rights, fees and conditions appropriate for the commerce models they select and provide standard terms for usage rights with useful, concise and easily understandable meanings. 
The license is usually a separate document. Take Windows Media Rights Manager as an example. A license in this system contains the following information [14]:

? The license version

? The key to play the music file

? A signature, which ensures that the license has not been tampered with.

? The rights of the license. By default, the consumer has rights to play a music file and to copy it to a portable device and play it.

? The application security level, which ensures that only applications with this or a higher level of security can use the license. By customizing the license acquisition, you can set the application security level for licenses.

? The expiration date of the license. By default, licenses do not expire. However, by customizing the license acquisition process, the user can set the number of days for which a license is valid. The expiration date is calculated when the license is issued. For example, if you set the license to be valid for 30 days, the license expiration date is one month after it is issued.

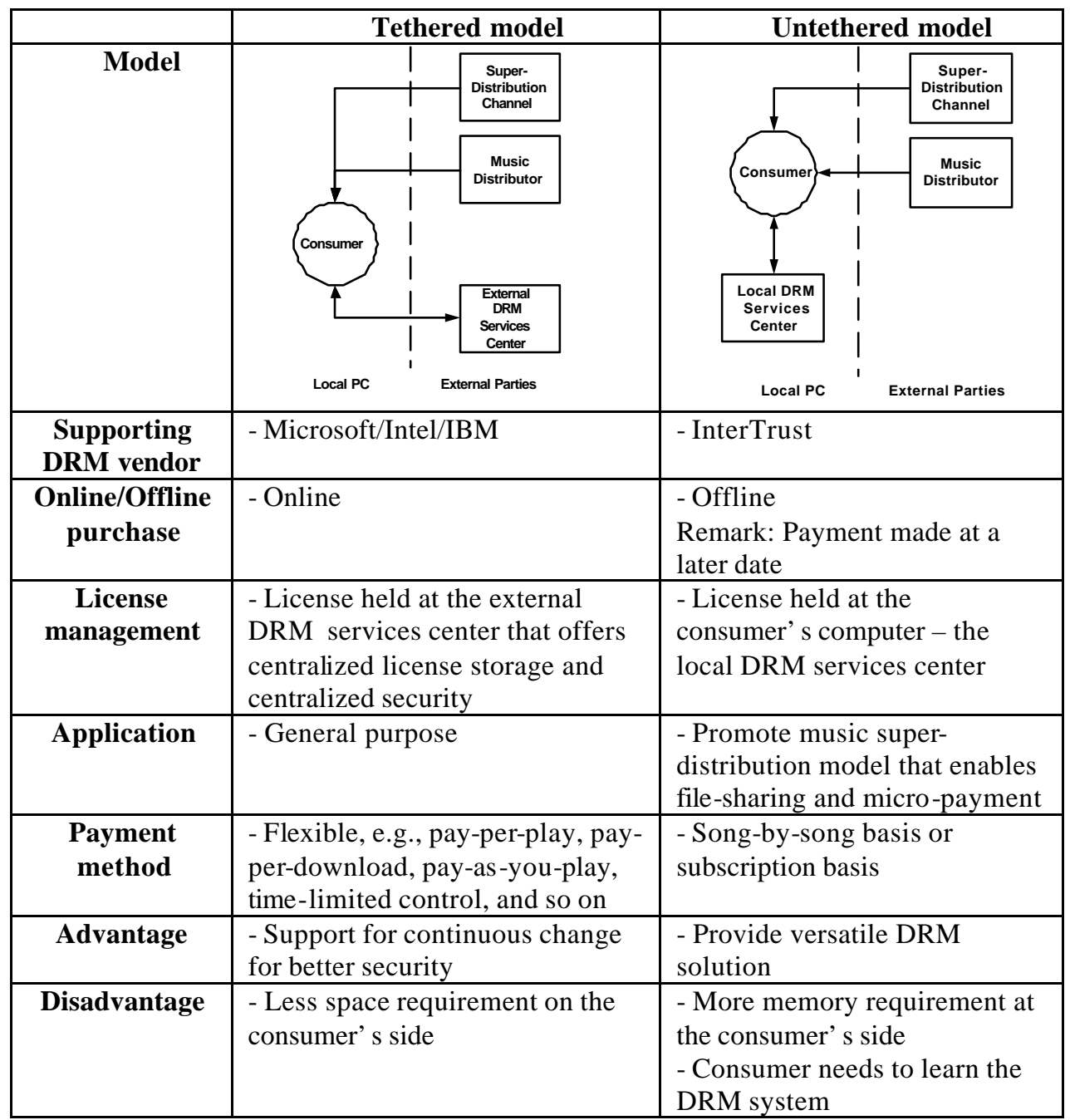

Table 1: Comparison between tethered and untethered models. 
DRM services center: A DRM services center is a mechanism that is responsible for hosting and issuing licenses to consumers. It manages digital rights on behalf of the content owner by controlling content licenses (the virtual keys that allow users to open/play secure digital music). It also stores and tracks information about the issued license and the rights-protected music. In different license management models, the DRM services center can be in the form of either an external or local module.

\section{ENHANCED LICENSE MANAGEMENT MODEL}

In this section, we propose an enhanced license management model for the online music business that basically offers both online and offline purchases, which consumers may find convenient. The enhanced model combines both the tethered and untethered models. In achieving this, a license management system that can handle these two different payment models is necessary.

Overview: In achieving the enhanced license management model, license management is crucial. The overview of the model with all concerned license management parties is presented in Figure 2. In the enhanced model, there are two DRM services centers, one residing in the consumer's computer, while the other one resides externally. Their roles are different; the external DRM services center provides a full set of license management services like the tethered model does, while the local DRM services center provides minimal license management services, which is a superset of the untethered model. In such a compensating license management setting, both online and offline purchasing are allowed. It is noted that the local DRM services center has to be a constrained external DRM services center in order to simplify and minimize the license management processing running in the consumer's computer. Performing license management in the consumer's computer is considered to be risky even when additional security and protection, such as encryption and authentication are used. If security and protection are taken into account in the local DRM services center, this usually leads to a highly complicated system being developed and training for the consumer becomes inevitable.

License management in the enhanced license management model should rely on the external DRM services center, where official licenses reside. The local DRM services center uses temporary licenses generated from rechargeable tokens or coupons. The rechargeable token or coupon is transformable to smaller-value and short-term licenses, which can be downloaded from the external DRM services center after registration and subscription.

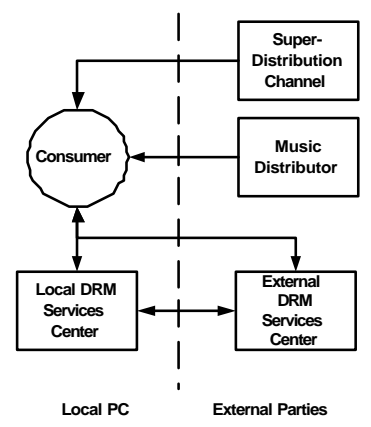

Figure 2: Overview of the enhanced DRM model.

Licensing in the Enhanced License Management Model: As there are two types of licenses, official and temporary used in the enhanced license management model, we 
show the differences between the two licenses and Microsoft's license in Table 2. Note that the Microsoft' s license is used in the tethered model.

\begin{tabular}{|l|l|l|l|}
\hline & $\begin{array}{l}\text { (i) Microsoft's } \\
\text { license }\end{array}$ & (ii) Temporary license & (iii) Official license \\
\hline Mode & Separate & Token/Coupon & Separate document \\
\hline $\begin{array}{l}\text { License } \\
\text { version }\end{array}$ & Needed & $\begin{array}{l}\text { Similar to (i) but for } \\
\text { temporary purpose }\end{array}$ & Same as (i) \\
\hline Key & Needed & $\begin{array}{l}\text { Generic for general use, } \\
\text { but will expire when the } \\
\text { expiration date is reached }\end{array}$ & $\begin{array}{l}\text { Same as (i) and replace } \\
\text { the temporary key at the } \\
\text { local DRM services } \\
\text { center }\end{array}$ \\
\hline Signature & Needed & Needed for the token & Needed \\
\hline $\begin{array}{l}\text { Security } \\
\text { level }\end{array}$ & Needed & $\begin{array}{l}\text { Should be higher than (i) in } \\
\text { order to prevent attacks } \\
\text { taking place at the } \\
\text { consumer' s computer }\end{array}$ & Same as (i) \\
\hline $\begin{array}{l}\text { Expiration } \\
\text { date }\end{array}$ & $\begin{array}{l}\text { Can be } \\
\text { customized }\end{array}$ & $\begin{array}{l}\text { Valid for a short period, } \\
\text { say 1 day }\end{array}$ & $\begin{array}{l}\text { Can be customized } \\
\text { depending on the } \\
\text { requests }\end{array}$ \\
\hline Purpose & General & Temporary use & $\begin{array}{l}\text { Permanent or } \\
\text { replacement purposes }\end{array}$ \\
\hline
\end{tabular}

Table 2: Differences between Microsoft' s, temporary, and official licenses.

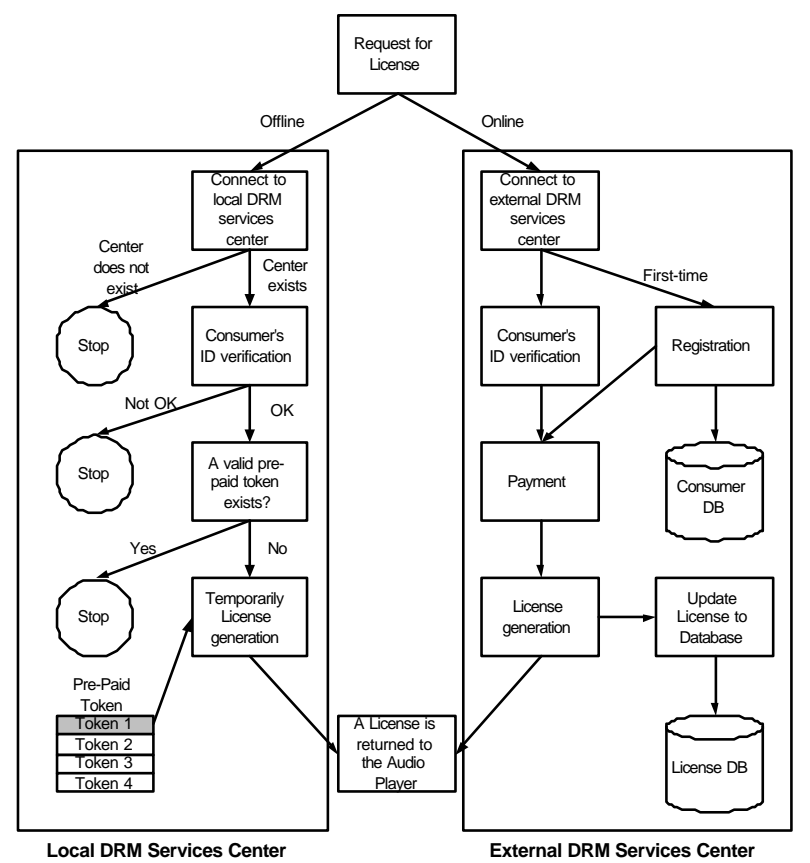

Figure 3: The license acquisition process in the enhanced license management model (using both local and external DRM services centers).

License Acquisition Process: When a consumer plays rights-protected music, the audio player will initiate the license acquisition process. The license acquisition process 
illustrated in Figure 3 will force the audio player to check whether the consumer has a valid license. If there is a valid license, the audio player can play the music. If there is no valid license, the license acquisition process will obtain either an official license from the official license site - the external DRM services center, or a temporary license from the local license site - the local DRM services center. The official license is always the preferable option. Therefore, if the consumer is online, the player will send client information, music identification, and consumer's private key to the external DRM services center. Otherwise the player will make a request to the local DRM services center for the temporary license if the local DRM services center exists. In producing a temporary license, the local DRM services center needs a music identification and a consumer's private key. The address of the external DRM services center is included in the digital music, while the location of the local DRM services center is known to the audio player when the token/coupon is downloaded from the official license site.

Therefore, the license acquisition process can be operated in either the external or the local DRM services center, depending on whether or not the consumer is able to connect to the external DRM services center.

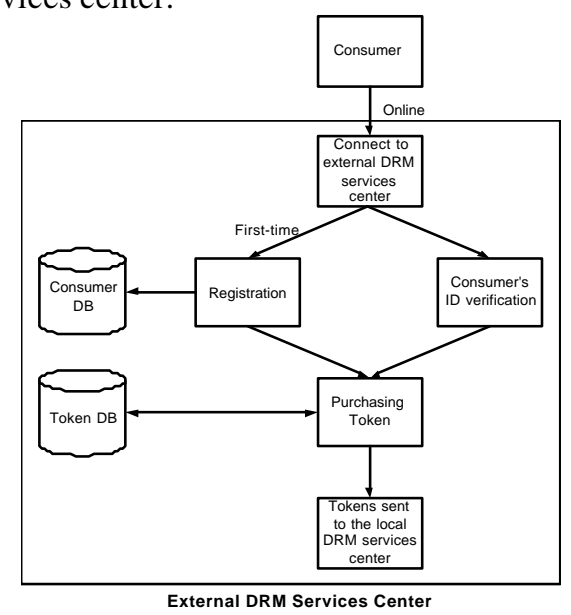

Figure 4: Subscription of pre-paid token in the enhanced license management model.

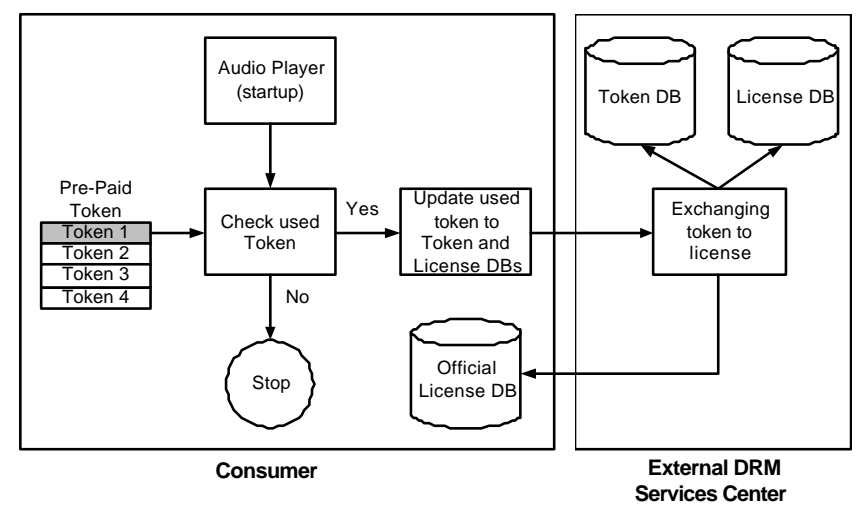

Figure 5: Exchanging used pre-paid tokens with a constrained official license.

In obtaining pre-paid tokens, a consumer must first register with the external DRM services center and purchase tokens there. This process is depicted in Figure 4. The "Purchasing Token" process extracts tokens from the token database and assigns them to a specific local DRM services center. The token database is used to store all unassigned 
and assigned tokens. Temporary licenses are usually valid for only a very short period of time. In order to continue to own the purchased music, the player will automatically exchange the used pre-paid token with a limited-usage or constrained official license subject to the terms of the token. The exchange process is described in Figure 5.

\section{CONCLUSIONS}

This paper presents an enhanced license management model that supports both online and offline purchasing for the online music business. The model is designed for digital rights management systems. The intent of the proposed model is to increase user satisfaction in DRM technology by providing various ways of accessing and using DRMprotected music and, to a certain extent other media contents. The proposed enhanced license management model has also been applied in the Peer-to-Peer environment [10]. Further research in this area includes a study on the application of a mobile platform and an investigation of successful business models that adopt digital rights management.

\section{REFERENCES}

[1] L. C. Anderson, J. B. Lotspiech, "Rights Management and Security in the Electronic Library." Bulletin of the American Society for Information Science, vol. 22, no.1, pp.21-3, Oct.-Nov. 1995.

[2] ContentGuard XrML Technology, 'Driving the Standard with XrML', http://www.contentguard.com/xrml.asp, accessed 27 March 2002.

[3] 'Digital Property Rights Language (DPRL)', http://www.oasis open.org/cover/dprl.html accessed 27 March 2002.

[4] F. Hartung, and F. Ramme, "Digital rights management and watermarking of multimedia content for m-commerce applications," IEEE Communications Magazine, Volume: 38 Issue: 11, pp. 78-84, Nov. 2000.

[5] IBM's Electronic Music Management System (EMMS), 'Computer Science Research at Almaden', http://www.almaden.ibm.com/cs/madison.html accessed 27 March 2002.

[6] Intel, 'Intel Software Integrity System Enhances Secure Online Distribution of Music, document, Video', http://www.intel.com/pressroom/archive/releases/in110999.htm accessed 27 March 2002.

[7] InterTrust, 'InterTrust', http://www.intertrust.com/ accessed 27 March 2002.

[8] J. King and P. Kudumakis, "MPEG-4 IPMP Extensions," Lecture Notes in Computer Science, 2320, Springer 2002, ISBN 3-540-43677-4, pp. 126-140, 2002.

[9] S. H. Kwok, S. C. Cheung, K. C. Wong, K. F. Tsang, S. M. Lui, and K. Y. Tam, "Integration of Digital Rights Management into Internet Open Trading Protocol (IOTP)," To appear in Decision Support Systems, 2002.

[10] S. H. Kwok, and S. M. Lui, "A License Management Model for Peer-to-Peer Music Sharing," To appear in the Special Issue on Virtual Organizations and E-Commerce Applications in the International Journal of Information Technology and Decision Making (IJITDM), Issue 3, 2002.

[11] A. Ramanujapuram and P. Ram, "Digital Content \& Intellectual Property Rights,"

Dr. Dobb's Journal, pp.20-27, December 1998.

[12] Superdistribution: Objects as Property on the Electronic Frontier. Brad Cox.

Addison-Wesley, 1996.

[13] "The major players, partners in digital-rights management; Anonymous," Billboard, Vol. 112, Issue 16, pp. 103, Apr 15, 2000.

[14] Windows Media Technologies, "Architecture of DRM", http://www.microsoft.com/windows/windowsmedia/wm7/drm/architecture.asp accessed 16 May 2002. 